\title{
Hospital Psychological Assessment with the Drawing of the Human Figure: A Contribution to the Care to Oncologic Children and Teenagers
}

\author{
Iracema do Vale Pinheiro ${ }^{1 *}$, Allyson Guimarães da Costa ${ }^{1,2}$, \\ Débora Cristina Bandeira Rodrigues ${ }^{3}$, Nália de Paula Oliveira4, \\ Adriana Malheiro1,5, Josafá Lima Ramos 6 \\ ${ }^{1}$ Departamento de Ensino e Pesquisa, Fundação de Hematologia e Hemoterapia do Amazonas (HEMOAM), \\ Manaus, Brazil \\ ${ }^{2}$ Programa de Pós-Graduação em Medicina Tropical, Universidade do Estado do Amazonas (UEA), Manaus, \\ Brazil \\ ${ }^{3}$ Departamento de Serviço Social, Universidade Federal do Amazonas (UFAM), Manaus, Brazil \\ ${ }^{4}$ Centro de Tratamento Psicológico (CENAPSI), Manaus, Brazil \\ ${ }^{5}$ Programa de Pós-Graduação em Imunologia Básica e Aplicada, Universidade Federal do Amazonas (UFAM), \\ Manaus, Brazil \\ ${ }^{6}$ Serviço de Psicologia, Fundação de Hematologia e Hemoterapia do Amazonas (HEMOAM), Manaus, Brazil \\ Email: ${ }^{\text {iracemapinheiro72@gmail.com }}$
}

Received 21 January 2015; accepted 24 March 2015; published 26 March 2015

Copyright (C) 2015 by authors and Scientific Research Publishing Inc.

This work is licensed under the Creative Commons Attribution International License (CC BY).

http://creativecommons.org/licenses/by/4.0/

cc)

\section{Abstract}

Cancer affects a large number of children and adolescents each year, and studies prove possible negative influences on the emotional state during the treatment of the disease. This study is part of the macro search entitled "Hospital Psychological Assessment Protocol: A Contribution to the care to Oncologic Patients", from which the data were extracted. The main objective of this study was to identify the emotional disorders in oncologic children and adolescents in the hospitalization process, through the DHF: Drawing of the Human Figure-DHF. It refers to a cross-sectional descriptive study, with qualitative method, with approach in psychoanalysis. The study included 10 oncohematologic children and adolescents, aged between 5 and 17 years and 11 months in the hospitalization process for cancer treatment in the Hospital Foundation of Hematology of the Amazon-HEMOAM. To obtain preliminary information, we used an Anamnese script in an interview with parents/guardians, after that, it applied the projective psychological test, in a maximum

\footnotetext{
*Corresponding author.
}

How to cite this paper: Pinheiro, I. V. et al. (2015). Hospital Psychological Assessment with the Drawing of the Human Figure: A Contribution to the Care to Oncologic Children and Teenagers. Psychology, 6, 484-500. 
time of 50 minutes. Among the main results identified in the research as emotional changes in the hospitalization process, it could be highlighted: hostility, narcissism, depression, preoccupation with themselves, aggression, insecurity, withdrawal, regression, anxiety and tension. The emotions that were prevalent throughout the period of hospitalization for chemotherapy were: aggression, insecurity, withdrawal, regression, anxiety and tension. The resources used by the child and the adolescent as strategies to tackle the disease were: regression, withdrawal, aggression and hostility. It is concluded that the instrument (DHF) allows psychological assistance which is performed without exposing the patient to content that permeates the hospital environment, thus favoring the therapeutic secrecy without interfering with hospital routine, but adapting to it.

\section{Keywords}

\section{Psycho-Oncology, Psychological Assessment Playful, Oncologic Children and Adolescents}

\section{Introduction}

The psycho-oncology offers emotional support to cancer patients, their families and professionals involved in the treatment (Veit \& Carvalho, 2008). In Brazil, according to these authors, historically cancer has been associated with emotional states, justifying the need to combine the treatment with psychological care to cancer survivors and their needs to deal with the healing of chronic condition or the possible feelings of insecurity resulting from illness, and the likely consequences, as well as their integration into new everyday routine.

According to Carvalho (2002), oncologist doctors in front of difficulties to inform the diagnosis of cancer to patients and their families, felt the need to request the help of teams of psychologists and psychiatrists.

When the man gets sick all their subjectivity is shaken and the psychologist's role is to listen to the sick person talking about themselves, sickness, life and death, fears and desires. While the doctor works with the physical body the psychologist works with the symbolic body, even if the patient is unable to speak, there are the nonverbal signs that give amount of words that express what relationship the patient has with his symptom, and especially the destination of the symptom (Simonetti, 2004).

According to Campos (1995) for proper psychological care to patients and their families, it is necessary to clarify the implications, the origin, development and treatment of disease; assess how the patient perceives themselves as a patient, the boundaries between the real and the imaginary, because for each individual the disease has a particular meaning. The patient can trigger, guilt regression and depreciation of themselves, causing a break in their personal history, each person experiences the hospitalization in a peculiar way.

The perception that the patient has, depends on their bases of psychological training because there is a need of maternal love for the mental health of the patient. Bowlby (1993) states that in the first years of life, family ties and a good atmosphere of affection, especially with their mother or caregiver is essential to ensure that the bases of psychological formation of the future adult are healthy, therefore, should be avoided intense ego trauma caused by the loss of the primary reference. The cause of insecurity in children is, above all, the physical and/or emotional absence of the mother or caregiver or the separation of these in the phases in which the child needs care and protection.

The transition from childhood to adulthood is marked by the definition of body image and the final personality structure, period in which the child goes through physical, mental and emotional changes (Bighetti \& Valle, 2008). In view put by Azevedo (1995) the social, mental and emotional maturation, is a period of great inner turmoil, of learning how to deal with new facts, emotions and forms of relationships.

After the diagnosis of cancer, the child and the adolescent are experiencing a routine marked by hospitalizations, amid strangers, painful procedures such as tests and medications, in addition to chemotherapy and radiotherapy that produce severe side effects such as nausea, vomiting diarrhea, fever and hair loss. In front of the unknown, the patient experiences feelings of failure, abandonment, fear of death, factors causing anguish and anxiety (Bighetti \& Valle, 2008).

The first hospitalization is the most extended, in which the patient must give attention to pre-established rules and hardly changed. Valle \& Ramalho (2008) corroborate that coping with the disease in an adverse condition; depends on the age, maturity level and how the child and the adolescent deal with adversities. 
However, it is necessary to evaluate the patient to identify the contents that the professional intends to investigate. Thus, the psychologist has psychological tests that provide a more accurate assessment to complement the listening and observation of non-verbal signs of the patient, helping to identify the alleged emotional changes and assist in preventive interventions during the service.

In the hospital setting, according to Belar (2000), a psychological assessment aims to identify the psychological repercussions caused by the disease process. In this perspective Stout \& Cook (1999) report that in the medical field has its relevance as a tool for decision-making relating to the differential diagnosis, type of treatment required and prognosis. Also for early identification of maladaptive emotions and behaviors and/or psychological and psychiatric disorders in patients enrolled in the hospital, providing the difference in the quality of care provided to the patient, as well as the reduction of psychological distress.

Capitão, Scortegagna \& Baptista (2005) confirm in order to use this tool in hospitals, it is necessary to their suitability to environmental characteristics, such as clinics or wards, due to routine procedures it is necessary to choose the type of instrument that should be well planned, so that the evaluation is not impaired.

Among the psychological assessment instruments, there is the design that before becoming a psychological test was already used to express feelings and thoughts. This instrument is one of the oldest means used to establish communication, even before the verbal and written communication (Bandeira, Costa, \& Arteche, 2008).

In Campos reading (1969) the intense researches on the symbol drawing gave perception to scholars that the unconscious is revealed through symbolic aspects of the drawing. Note that the instrument offered security in the results for the diagnosis and prognosis of personality traits, besides being an easy test to manage, in a short period of time and with considerable quantification of the results.

With the establishment of the design as psychological evaluation technique, psychologist researchers, currently, use it in various areas of psychology. Aberastury (2012) states that the scientific recognition of design as a means of expression of the child, occurred when it was studied its meaning from the psychoanalytic point of view.

With this argument, Hultz \& Bandeira (2000) introduced the Drawing of the Human Figure-DHF as a test that has a comprehensive technical, objective and easy to apply. It is used with children and adolescents, in order to assess the personality, emotional adjustment, the conceptual maturity and anxiety, because the patient expresses in the figure their own image and draw their IDs and conflicts, a timely tool for psychological assessment of the particularities in the affective field.

\subsection{Justification}

The hospitalization process for the treatment of cancer is a period in which the child and the adolescent experience the separation of the people with whom have emotional bond, change of physical space, school dropouts, their groups and friends, going to experience a hospital routine with invasive and painful treatment procedures, causing fear and suffering and death emotions.

Given this context, from psychological assistance to cancer children and adolescents through curricular stage developed in the Hospital Foundation of Hematology of the Amazon-HEMOAM, it was realized the need of a psychological hospital system through instruments of evaluation and psychological intervention with games features. Developing activities aimed at identifying possible emotional changes, minimizing the effects of hospitalization and prevent the outbreak of psychological suffering, enabling the active participation of patients and their families in the process of treatment and recovery from illness. The proposal originated the macro research entitled "Hospital Psychological Assessment Protocol: A Contribution to Assistance to Cancer Patients", from which the data for this study were extracted: "Hospital Psychological Assessment with the Drawing of the Human Figure: A Contribution to Assistance Cancer Children and Adolescents”.

It is important to point out that research macro, was held under the Support Program for Scientific InitiationPAIC/HEMOAM in August 2013 to July 2014, and was funded from the Foundation to the Amazonas State Research-FAPEAM.

The study had as a suggestion an instrument to systematize and plan the hospital psychological assistance. In this sense, this research contributed to the identification of emotional alterations of cancer children and adolescents in the process of hospitalization through Psychological Assessment of the DHF test, contributing to the improvement of psychological intervention strategies, assisting in patient adherence to treatment, their relationship with the health care team, family members involved and interaction, as well as response to treatment, providing quality of survival. 
This study aimed at one psychological assessment instrument with playful characteristics to be the target audience, cancer children and adolescents in physical and mental conditions of vulnerability, so that this does not become another invasive procedure, but favors the hospital psychological assistance. Targeting an instrument to systematize and plan a hospital psychological care. Contributing to the identification of emotional changes, the improvement of psychological intervention strategies, assisting the patient to adhere to the treatment, their relationship with the health team, family members involved and interaction, as well as answer treatment providing quality of survival.

\subsection{Problem}

The process of cancer treatment requires a prolonged period of hospitalization, in which the patient is subjected to invasive and painful procedures during chemotherapy. Whereas this may bring emotional changes, and even trigger psychopathology, before this context, the central question to be answered by this research is: What are the emotional disorders in children and adolescents in the hospitalization process for cancer treatment?

\subsection{Objectives}

Among the proposed objective in the research was to Identify the main emotional disorders in cancer children and adolescents in the hospitalization process, by Drawing of the Human Figure, being specific to Identify the predominant emotional changes in the hospitalization process; and Investigate the coping strategies of disease for chemotherapy treatment; Describing psychological assistance from DHF.

\section{Methods}

Regarding the type of research it is characterized as a cross-sectional descriptive study with qualitative method, the basic element of research is the subjectivity, with approach in psychoanalysis, and Bardin content analysis (Bardin, 2011).

As the research subjects participated in the study 10 children and adolescents with blood cancer aged 5 - 17 years and 11 months old, in hospitalization for chemotherapy, users of HEMOAM Foundation services. Exclusion criteria: Patients with Down syndrome.

According to HEMOAM database, Idoctor, from 2012 to May 2014, the number of patients with a diagnosis is 2054 (made a review of the data), of these, 280 patients, aged 5 - 17 years and 11 months, have some type of blood cancer, with a prevalence of around 13\%. Therefore, for this population and with that prevalence the number of patients to be interviewed (sample) with a margin of error of $5 \%$ and reliability of $95 \%$ is proportional to 160 patients.

With regard to instruments, to obtain preliminary information, we used an Anamnese script in an interview with the parents/responsible. The identification of emotional changes took place from Psychological Test with application of DHF, while collecting data for macro research. In which we used a Psychological Assessment Protocol which consists of a clinical history script Anamnese, answered by parents/guardians; and Psychological Testing: DHF: Drawing of the Human Figure, from the HTP: House-Tree-Person (Buck, 2009); CAT-A: Children's apperception test (animal figures); TAT: Thematic Apperception Test. And psychodiagnostic instruments Interventive: Game Tunnel Time and Deck of Emotions.

The DHF: Drawing of the Human Figure was selected for this study because it was easily accepted, more applicable and in a short period of time, with an application rate of $80 \%$ of the 20 research participants macro, saved the exceptions given to impossibility of the use of the hands due to nursing procedures.

Data collection began with psychological care, with a sequence undetermined visits to the patient's bed in a ward. After establishing rapport with the child, cleared the content, the need and the importance of research into parents/guardians, goals exposure, and technical and ethical aspects.

The anamnesis script was applied to the parents/guardians individually, seeking a placeholder of the presence of the patient, and possible privacy policy. However, in some cases the interview was conducted in the patient's presence because it was not responsible to leave the ward, due to chemotherapy procedure, or even simple resistance. This phase of collection aimed to harvest personal information, such as identification data, hospital history, past and current history of the patient.

The instruments were applied individually at bedside during their stay in hospital, the maximum time of 50 
minutes respecting the participant's availability and responsiveness. However, were not used all the tools in a single patient, because the applicability proceeded according to demand and the affinity of the patient by the instrument. However, it was possible to apply up to three instruments per patient.

Note that macro collection of data of research not only configured in obtaining data by testing, but also in psychological assistance to participants during their stay in hospital, and in some cases the return of these in the continuity of chemotherapy. Therefore, enabling the establishment of the therapeutic relationship, the observation of the patient, and to compare the data obtained from the psychological test with listening and non-verbal signs of children and adolescents, enabling confirmation of results obtained with DHF and when possible psychological intervention.

It is important to mention that this study was submitted to the Research Ethics Committee (CEP) of HEMOAM Foundation, and complied with the ethical principles in research with human beings, according to the criteria of the National Health Council in Resolution 466/12. Participants were identified by numerals, protecting their identity. There was not, by the participants or Parents/Guardians, the request to exclude the research.

As for benefits: The study had as a suggestion an instrument to systematize and plan the hospital psychological assistance. In this sense, this research contributed to the identification of emotional alterations of cancer children and adolescents in the process of hospitalization through Psychological Assessment of the DHF test, contributing to the improvement of psychological intervention strategies, assisting in patient adherence to treatment, their relationship with the health care team, family members involved and interaction, as well as response to treatment, providing quality of survival.

As for the risks: During the implementation of the instruments, the patient may experience clinical instability. One should be aware of verbal and nonverbal communication of the same, note the presence of reactive symptoms, so that the procedure does not become invasive. However there was no clinical instability during the application of the instruments.

\section{Results}

The results obtained for the emotional changes during the period in which children and adolescents were hospitalized are common feelings with low psychological risk arising in the first days of hospitalization and reduce after a few days. Veit \& Barros (2008) explain that the hospital stay awake emotional reactions such as feelings of helplessness, physical discomfort experience, fear before new procedures and uncertainty as to discharge.

\subsection{Emotional Changes in Oncohematologic Children and Adolescents in the Hospitalization Process}

The results obtained for the emotional changes during the period in which children and adolescents were hospitalized are common feelings with low psychological risk arising in the first days of hospitalization and reduce after a few days. Veit \& Barros (2008) explain that the hospital stay awake emotional reactions such as feelings of helplessness, physical discomfort experience, fear before new procedures and uncertainty as to discharge.

Figure 1 highlights the emotional changes that were identified in the psychological test, from four participants when they had the same emotional changes.

It was found that among the emotions that emerge in children and adolescents in the period they are hospitalized (Figure 1) there was a prevalence of $100 \%$ to insecurity, withdrawal, regression, anxiety and tension, however, are also emotions that dominate the process hospitalization for chemotherapy (Table 1). Aggression and hostility characterized as a coping strategy (Table 2).

\subsection{Changes Emotional Predominant in Chemotherapy Treatment}

Refers to the prevailing changes (Table 1) during hospitalization in which the patient undergoes procedures for the use of chemotherapy. Identified emotions were highlighted individually in the psychological testing of participants, those containing at least three replications. Such emotions, for its prevalence, mobilize the patient to high levels of psychological distress, and to stay for a prolonged period, it may interfere with medical procedures, the relationship with the health team and family members involved in the treatment, acceptance of the disease condition and up even cause psychopathology and therefore the response to chemotherapy. 


\section{Number of Patients (N.P.)}

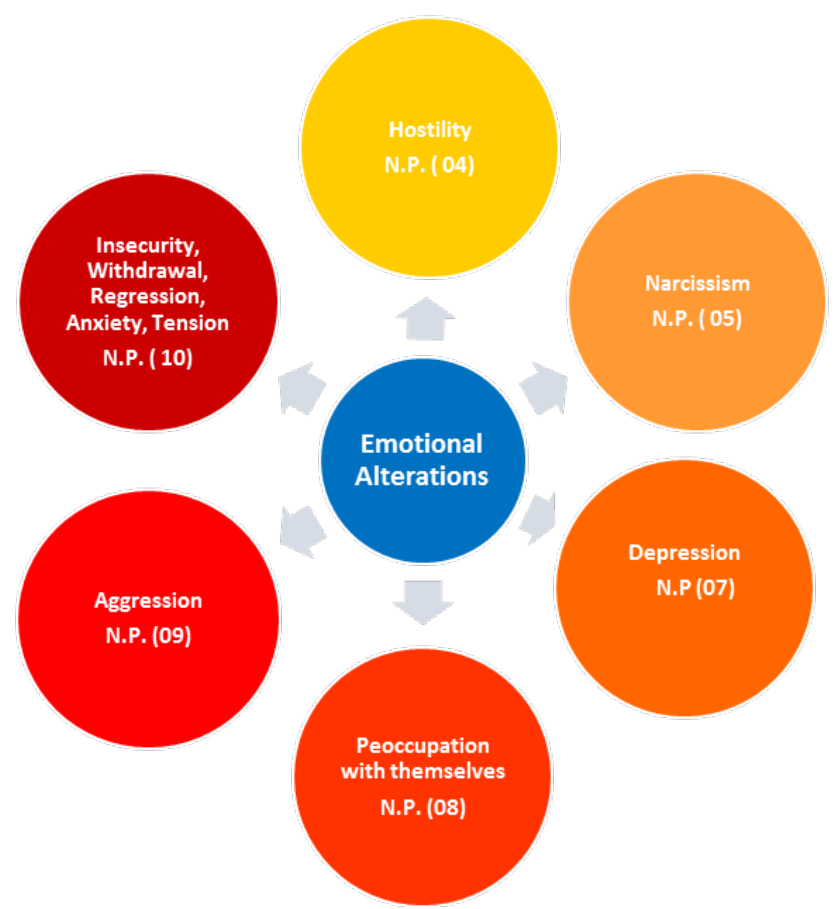

Figure 1. Results obtained in test psychological DHF, for emotional changes in hospitalization process.

Table 1. Results obtained in test psychological DHF for emotional changes predominant in chemotherapy treatment.

\begin{tabular}{cc}
\hline Emotional changes predominant & Number of patients \\
\hline Tension & 04 \\
Insecurity & 07 \\
Withdrawal & 07 \\
Regression & 07 \\
Aggression & 08 \\
Anxiety & 09 \\
\hline
\end{tabular}

Table 2. Results obtained in test psychological DHF for coping strategies of the disease in chemotherapy treatment period.

\begin{tabular}{cc}
\hline Coping strategies & Number of patients \\
\hline Hostility & 04 \\
Withdrawal & 07 \\
Aggression & 08 \\
Regression & 09 \\
\hline
\end{tabular}

The results for emotional changes in chemotherapy are also results for emotional changes in the hospitalization process, and even emotions present in all the participants of this study, however, what differentiates the results is the predominance, which refers to the amount of repeats found in each patient's psychological test.

Withdrawal, regression and aggression, are also emotions identified as resources used by children and adolescents to tackle the disease (Table 2). 


\subsection{Coping Strategies of the Disease in Chemotherapy Period}

The coping strategy investigated in this study (Table 2) refers to behavior used by children and adolescents, to deal with the stress agent during their stay in hospital for chemotherapy. Compas et al. (2001), consider that the strategy involves active efforts to achieve some personal control over the stressful aspects of the environment and the emotion itself, which also includes commitments to adapt to a situation through acceptance. Valle \& Ramalho (2008) confirm and add that to cope with the disease in an adverse condition, depend on the age, maturity level and how the child or adolescent deal with adversity.

\subsection{Psychological Cares from the Drawing Human Figure-DHF}

This item is specifically intended to describe how happened to psychological help to oncohematologic children and adolescents. To this end was selected among the 10 participants in this study, the case of a child, hospitalized for 30 days, which will be identified by numeral (Patient 06), according to the methodology set out in the macro research. The choice was made to have been the case in which it was possible to cover all procedures in a hospital psychological assistance from the proposed protocol.

P06 (Figure 2), female, 8 years old, Catholic, born in the interior of Amazonas only daughter of the couple, has a maternal brother 17 years old. First hospitalization, therefore, had just received the diagnosis. She was accompanied by her mother. To be addressed by the researcher she was very receptive. It was clarified about the psychological care in the hospital, the research protocol and the continuity of psychological care. After acceptance, they signed the Terms and completing the medical files. Established rapport, we sought to keep the daily visit, keeping the listening and observation, because the newly diagnosed, and then asked to P06 to developing the design, which demonstrated great interest and concentration on the task.

The person was drawn at arm's length receptively, signaling a need for affection. It is located right of the page, denotes that has the ability to delay gratification, is stable and is able to control their emotions. However, has a high level of anxiety and insecurity, indicated by the soil line and is also present in the erasures. The person is closer to the bottom of the page and on a solo line, also an indicator of uncertainty.

P06, careful not to disappoint his parents because his father also was sick at the same time she was hospitalized, her mother reported to verbalize that her daughter was stronger that the mother and both requested to the child the child not to cry. In this scenario the smallest was not crying, and showed stable behavior, tightly controlled, always verbalizing be happy. Was conducted to clarify the mother and the need for the child to express what the child was feeling on condition of hospitalization/illness, and asked parents not to keep him from crying. However there was no success, because the child started to bring in his speech, which had been crying. It was noticed that the entire child's body began to tremble, and the shaking grew every day.

After investigating and found that it was no organic cause, it was concluded that there was a somatization symptoms. In response to patient was held intervention with the discourse of confrontation of the patient and his real situation was performed.

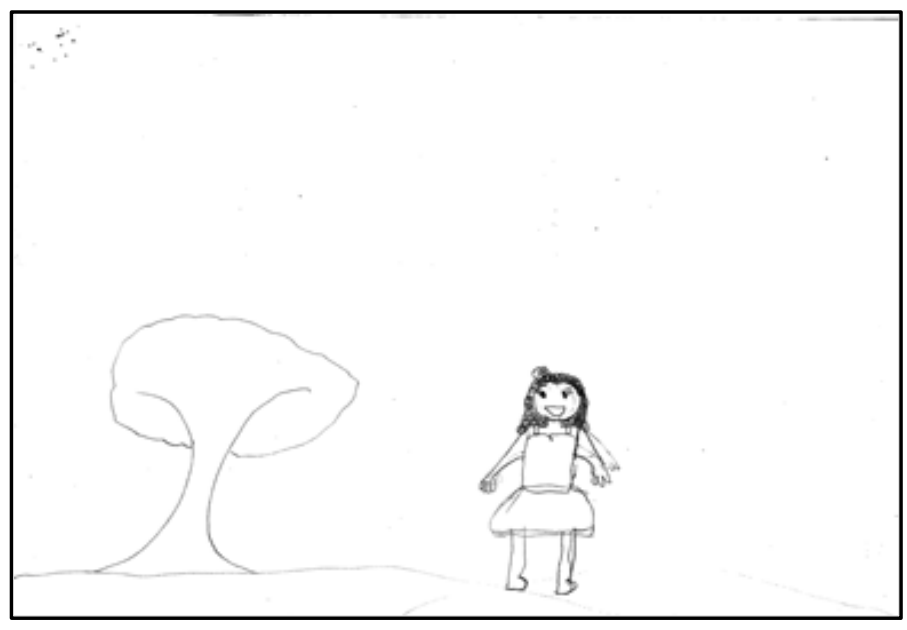

Figure 2. Patient 06, female, 8 years old. 
In a subsequent visit, the mother reports that at one point, the child asked to go to the bathroom where she began to cry, telling her mother she was very sad, because it is much pain, so much suffering and not take it anymore. She went to the mirror, he was looking up, rubbing his hair, and told his mother that the psychologist told her to let it get out of her. She cried for a long time, said she would win and asked her mother to pray with her.

It is important for children to express what they feel, so they can pass the disease realistically. Buck (2009) states that when a person's figure is to the right of the page, this is more likely to show a stable behavior, postpone their immediate needs and impulses preferring intellectual and emotional satisfactions. It is overly concerned with the future and with those who share their environment and their opinions. So the patient had control of their emotions, not allowing dealing with their grief losses suffered as a result of hospitalization/illness, out of concern for the suffering of their parents and fear of losing the love of these.

\section{Discussion}

When the patient is admitted to make cancer treatment or to start treatment after diagnosis or to continue the cycles of chemotherapy, the patient remains hospitalized for a period of 5 to 30 days, or according to their clinical condition, when this patient is clinically unstable and needs to be transferred to other procedures.

Narcissism presented by $50 \%$ of participants was observed in their conduct, when they demand total caregiver's attention to the point that mobilizes it in their daily activities. Otherwise, it also refers to the multidisciplinary team, especially the psychologist, when the patient refuses psychological care if the professional give them assistance and also meet others who are in the same ward. Narcissism designed through drawing the human figure is represented by the drawing in which the person is drawn with heavy or light clothing. As it can seen in the drawing of Figure 3, in which the adolescent drew the person with little clothing, not only in the male figure, but when he was asked to draw a person of the opposite sex, this also designed the female figure with little clothing. Yet this perspective, the opposite can be seen in Figure 4 and Figure 5, in which the design is presented with a lot of clothes.

Depression is present in the person drawing when the location of it is at the bottom of the page, as can be seen more clearly in Figure 5. Depression being investigated it is a reactive depression, which occurs in the process of hospitalization/illness when the individual is faced with its limitations, with their losses and go through a grieving process, which requires a period for preparation. To Simonetti (2004) is a period of sadness, in which silence prevails and the person surrenders passively to their disease, which does not believe that they can be cured, not afraid of death, nor will to live. Angerami-Camon (2010) points out that depression in hospital circumstance there is a saddening, however there are existential perspectives and the sense of loss is perceived by the individual.

Preoccupation with themselves, was identified in eight of the ten participants, except for Figure 6 and Figure 2, refers to the location of the person on the left side of the drawing page. The concern that children and adolescents present in hospitals for cancer treatment, is very present in all that relates to their self-image and fear of death. Mostly teenagers are apprehensive when they receive the news that possibly due to chemotherapy, the hair will fall, but have a hard time to verbalize. However, children tend to cry because they are more expressive, and verbalize their fear. Bighetti \& Valle (2008) report that the stressful event for children and adolescents is the change in self-image, especially as a result of hair loss. Because look different from their peers, invokes a feeling of inadequacy, leading the young to avoid the group and isolate themselves falling in solitude.

Based on these in Table 2, the tension is closely linked to anxiety, being intensified by high levels of anxiety as a result of insecurity that the patient has the disease condition, the unknown that is their clinical picture, and treatment. The tension is identified in the drawing, when it has a very large size relative to the page (Figure 6) and by the drawing line quality, the line layout is very strong, as can be seen in Figure 7.

Insecurity, can be seen in the drawing person (Figure 8) characterized in size when small relative to the page. Similarly, the location of the design on the bottom of the page is shown in Figure 2.

The insecurity results from other feelings, such as fear, fear of the unknown; fear of death; fear of being abandoned by their parents, to being admitted to hospital without having the information about their medical condition and the procedures to be performed. Freitas (2008) adds that the child or young person should be informed of their hospitalization condition, because the more they know about their diagnosis and treatment procedures to be performed, less emotional changes will trigger during their stay in hospital. 


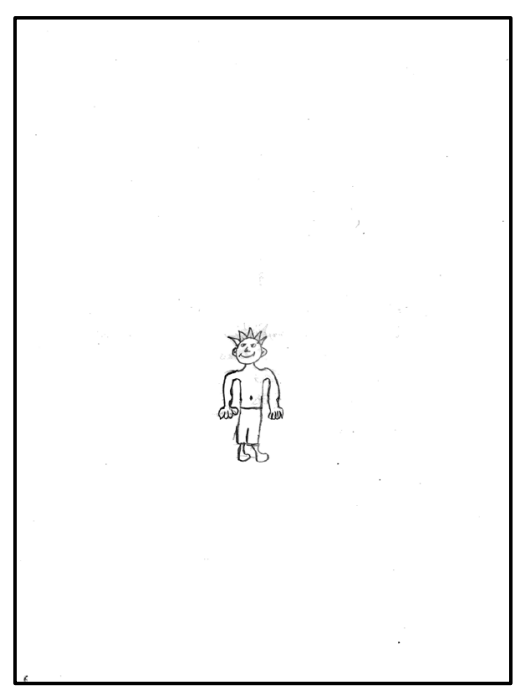

Figure 3. Patient 01, masculine, 16 years old.

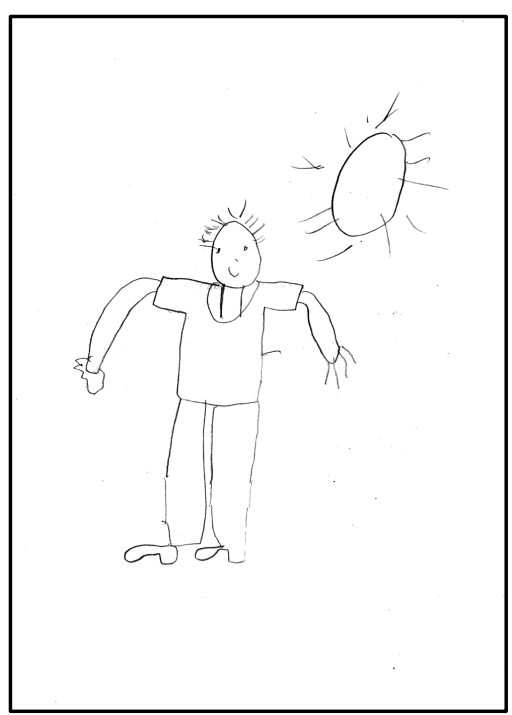

Figure 4. Patient 04, masculine, 7 years old.

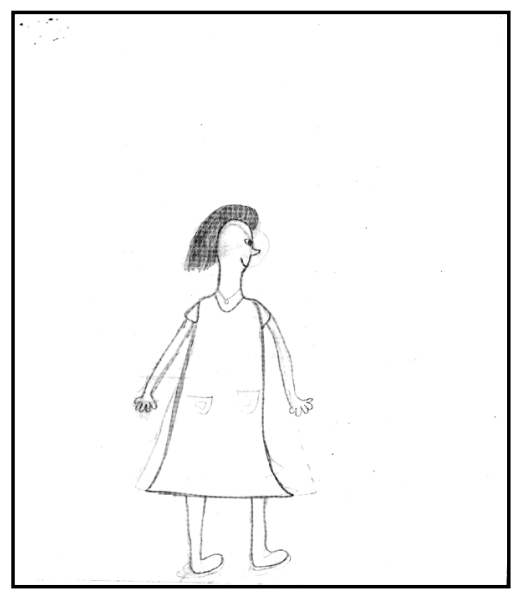

Figure 5. Patient 02, female, 11 years old. 


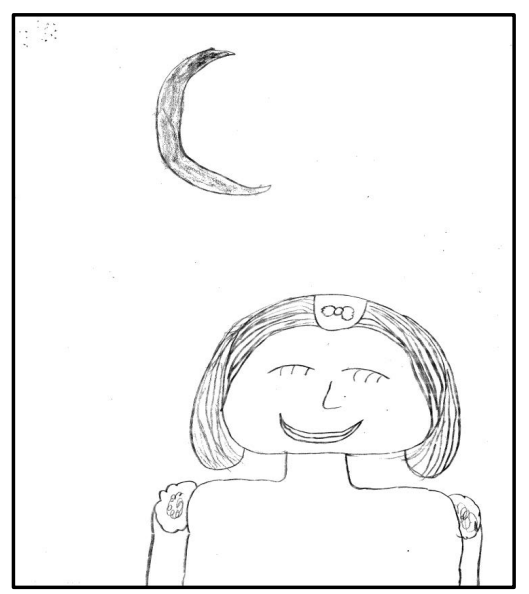

Figure 6. Patient 03, female, 9 years old.

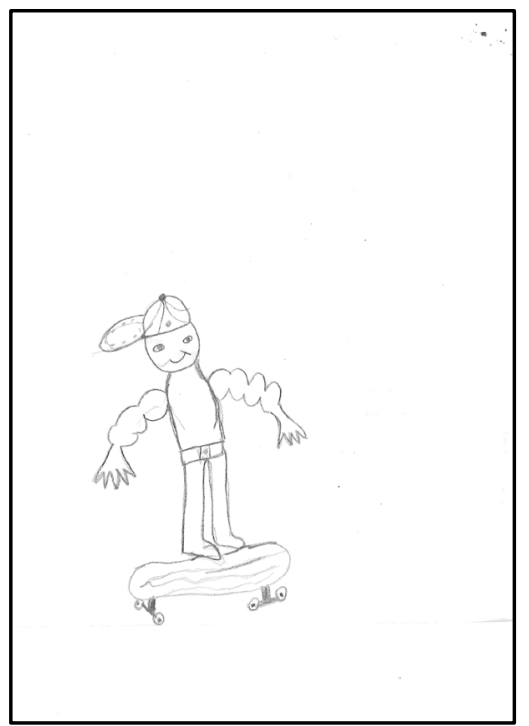

Figure 7. Patient 03, masculine, 12 years old.

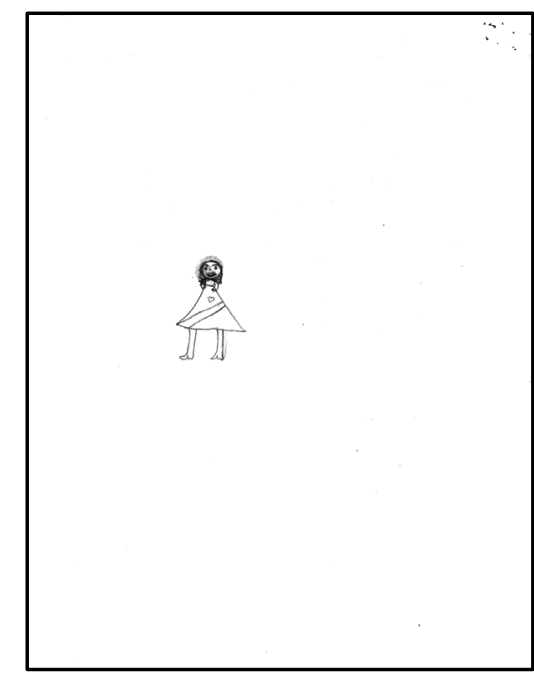

Figure 8. Patient 05, female, 8 years old. 
However, consistency in the conduct of the parents was observed in not to talk the actual condition of the child, tried even omit the diagnosis. A generating condition of anxiety as the child begins to raise questions about why so many medications and the long period of hospitalization.

Anxiety was identified by the quality of drawing line quality where it is very strong, as can be seen in Figure 7; by moderate distortions in the person drawing; erasures made during the execution of the design, drawing and erasing many times the same design (Figure 3) and when the ground line is drawn (Figure 2).

The anxiety this very present in the hospital expectation reinforced by the shared environment, being a ward with two to four beds, the child or adolescent witnesses that their college is discharged. Otherwise, parents who long for solving their problems outside the hospital, as had their routine interrupted going to experience their daily life inside the hospital, tend to reinforce this emotion in their child when arrange luggage even before the document discharge in hand, just for the alleged possibility of discharge. Moraes \& Enumo (2008) add that anxiety is also from the withdrawal from social life and loss of individuality, with its modified routine and marked by limitations of daily activities and unwanted compliance and rules and schedules. Feeling also generated by painful procedures such as collecting material for examination, usually performed after chemotherapy cycle, and intravenous medications.

Hostility, which can be seen clearly in Figure 6, is characterized by the person drawing in which the shoulders are square or emphasized, and likewise in Figure 7, the person drawing the rough hand has fingers are sharp.

Hostility, during hospitalization, was seen in patient care during the bed when they were resistant to taking medication, refusing directly or omitting to hide the tablet in their mouth for at an appropriate time to drop it. There is also resistance to feeding of a physiological condition due to nausea and vomiting caused by side effect of chemotherapy and other medications associated with the environment, the smell of the food, the disease condition and psychologically produce the same reactions. Bighetti \& Valle (2008) added that hospitalizations experienced by the patient during the treatment of cancer, are marked by painful procedures consist of a battery of tests, medications, chemotherapy and radiotherapy that produce severe side effects such as nausea, vomiting, diarrhea, fever and hair loss.

The Withdrawal was perceived as an emotional appeal shutdown of the hospital environment and all that is related with it, by patients and especially children. Compas et al. (2001) mentions that the child uses as poweroff, avoidance of the stress factor or own emotion, distraction through positive thoughts and activities.

Withdrawal is present at the drawing ratio, that is, the size of the figure relative to the page. In relation to the observer in front of the drawing, when person is viewed from the bottom (Figure 8) and either a distance (Figure 9).

Withdrawal were identified when the patient is collected in his bed, with no clinical or physical discomfort, the simple act or refusal of any contact with the multidisciplinary team or the other patients. It was noticed when the child during hospitalization maintains a neutral stance, even though the environment, does not integrate it; does not establish contact with patients in the neighboring bed, and rarely establishes dialogue with the psychologist, but does not refuse his presence, the same behavior is repeated with a multidisciplinary team that provides their assistance. It was noticed when the child during hospitalization maintains a neutral stance, even though the environment, does not integrate it; does not establish contact with patients in the neighboring bed, and rarely establishes dialogue with the psychologist, but does not refuse his presence, the same behavior is repeated with a multidisciplinary team that provides their assistance.

The Aggression is represented in the person drawing when it is drawn with legs apart. It can be identified also in feet robed figure (Figure 10).

Was observed aggressive behavior in an adolescent under the impact of the diagnosis in a state of revolt, during the psychological, expressed extreme anguish is collecting under the blanket, she cried not want to talk. This behavior occurs most frequently with the nursing team, which is a constant target of the anger of patients, through verbal abuse, denial of medicines, food, complaints and claims. Kubler-Ross (2008) reports that it is very difficult for family and hospital staff deal with the stage of anger. She spreads in all directions and projects on the environment, usually without good reason.

What happened did not happen in the first visit, in previous visits the teen established dialogue and held the psychological test. The revolt facing a diagnosis of cancer, where the patient's life activities are stopped abruptly and this needs to be confined to a hospital, subjected to unpleasant examinations, limitations and restrictions, receiving blood transfusions and platelets, with constant punch entry intravenous drugs, including 


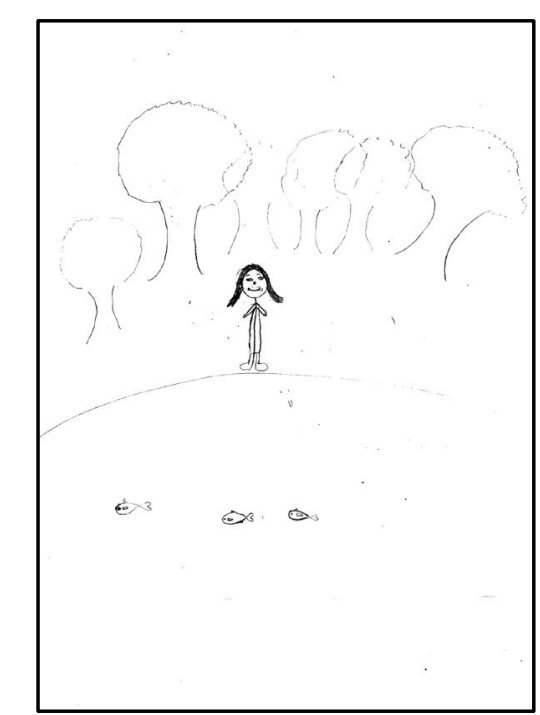

Figure 9. Patient 09, female, 13 years old.

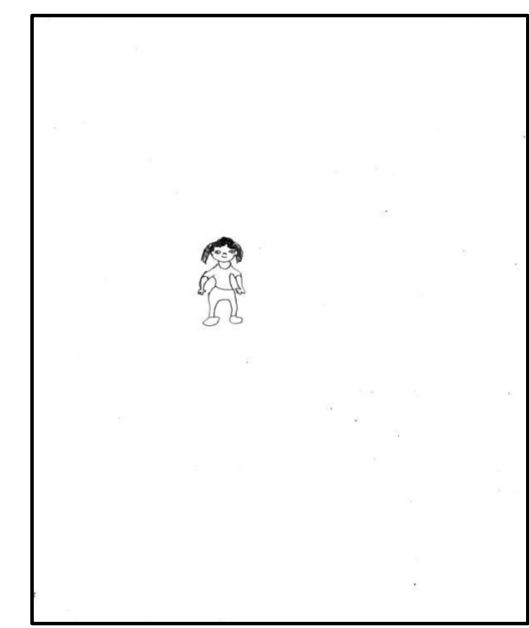

Figure 10. Patient 01, female, 10 years old.

chemotherapy. In this context, it is necessary to analyze the reason for the explosion of the patient, without taking it personally, because in its origin there is no grating with the person to whom the aggression is directed only a condition of the patient revolt.

The regression is a determinant of psychological distress, in which the subject regresses to earlier stages of development, adopting a proportionate conduct to the age at which installed a trauma. Oliveira, Dantas \& Fonseca (2004) in child hospitalization is restricted to the bed, in a passive condition, surrounded by strangers, with pain and suffering represented by needles, cuts, and medications, leading to discomfort experienced as confusing and threatening. It is common the development of defense mechanisms as regression, where the child returns to a previous phase to its development as a form of protection.

The regression was expressed in (Figure 11), in which the adolescent behaviors presented as eating only if given in the mouth by the mother, in the first admission. And later, the second hospitalization, had adopted an attachment object (stuffed puppy) with which remained during the day in his bed, and reported by his mother, the patient did not sleep without it. The need of maternal love in the first years of life for the mental health of the subject. Bowlby (1995) in addition to cognitive and physical care, the child needs a host and affection environment. The emotional bond between the child and his family, and especially with their mother or caregiver ensures that the foundations of psychological training of future adult are healthy, avoiding the intense trauma ego. Campos (1996) adds that the adolescent phase culminates in the process of separation/individuation of symbiotic 


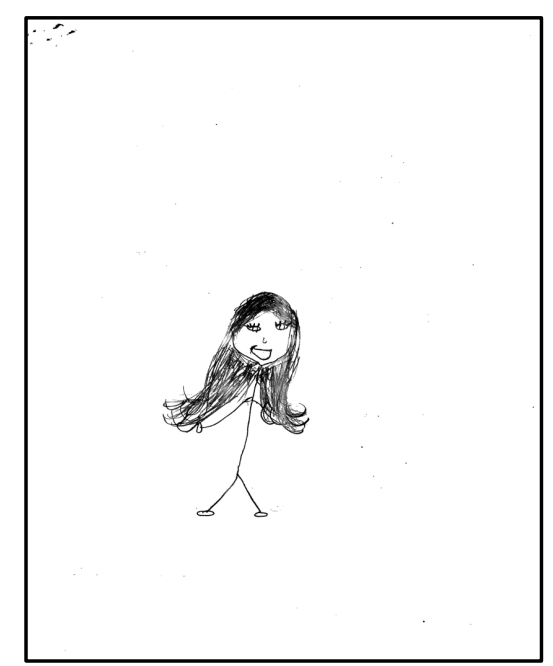

Figure 11. Patient 04, female, 14 years old.

relationship of dependence with the parents, object relations of full autonomy.

The teenager in his early childhood his father suffered separation and affective absence of his mother, a favorable condition for a possible trauma ego. Represented by the drawing of the person, carried out by patient. Aberastury (2012) mentions that the child - he was five years old already has the ability to perform the drawing of the human figure correctly, and that the deformations found in this representation, such as, lack of clothing, corresponding to internal conflicts.

\section{Conclusion}

The psycho-oncology can intervene on psychosocial disturbances added to the diagnosis and treatment of cancer that affect the development and survival of disease. The psychological assessment, used in investigative proceedings, provides tests to complement the listening and observation, helping to support the preventive interventions.

It could be observed that the application of DHF, in playful feature, was easily accepted by the participants; they were responsive mode of care, thus enabling the psychological evaluation. However, during application, most of them preferred not to answer questions concerning the person of the design. Thus, it was decided to let the patient express their emotions through drawing. Because for the hospitalized child, drawing is configured only as a moment that this has to play.

In view of the observations realizing in hospital context and condition of physical and psychological vulnerability, it is suggested that during the implementation of DHF, the psychologist allows the patient to draw free interrogative, and for additional information, beyond history, preserve and use listening and observation, thus minimizing the psychological testing of printing, front of the patient, avoiding more invasive procedures and preserving the playful.

\section{Acknowledgements}

The authors acknowledge the financial support provided by the Fundação de Amparo a Pesquisa do Estado do Amazonas (FAPEAM) and Conselho Nacional de Desenvolvimento Científico e Tecnológico (CNPq).

\section{References}

Aberastury, A. (2012). Child Psychoanalysis-Theory and Technique (8th ed.). Porto Alegre: Artmed.

Angerami-Camon, V. A. et al. (2010). Hospital Psychology: Theory and Practice (2nd ed.). London: Pioneer Thomson Learning.

Azevedo, G. (1995). Adolescence: The Teacher’s Book. São Paulo: Scipione (Peer Support).

Bandeira, D. R., Costa, A., \& Arteche, A. (2008). DHF Validity Study as Children's Cognitive Development Measure. Psy- 
chology: Reflection and Criticism, 21, 332-337.

Bardin, L. (2011). Content Analysis. São Paulo: Editions 70.

Belar, C. D. (2000). Psychological Interventions and Health: Critical Connections. Psychology, Health \& Diseases, 1, 11-17.

Bowlby, J. (1993). Distress and Separation: A Literature Review. In J. Bowlby (Eds.), Separation: Anguish and Anger (2nd ed.). São Paulo: Martins Fontes.

Bighetti, A., \& Valle, E. R. M. (2008). Understanding the Experiences of Teenagers with Cancer: Phenomenological Analysis of TAT. In Themes in Psycho-Oncology. São Paulo: Summus.

Buck, J. N. (2009). HTP: House-Tree-Person, Drawing Projective Technique: Interpretation Guide (2nd ed.). São Paulo: Vector.

Campos, D. M. S. (1996). Child Psychology and Adolescents (15th ed.). Petropolis: Voices.

Campos, D. M. S. (1969). Drawing Test as Personality Diagnostic Instrument (38th ed.). Petropolis: Voices.

Campos, T. C. P. (1995). Hospital Psychology: The Psychology Practice in Hospitals. São Paulo: EPU.

Capitão, C. G., Scortegagna, S. A., \& Baptista, M. N. (2005). The Importance of Psychological Assessment in Health Psychological Assessment. University San Francisco, 4, 75-74.

Carvalho, M. M. (2002). Psycho-Oncology: History, Characteristics and Challenges. Psycho-USP, 13.

Compas, B. E. et al. (2001). Coping with Stress during Childhood and Adolescence: Problems, Progress, and Potential in Theory and Research. Psychological Bulletin, 127, 87-127. http://dx.doi.org/10.1037/0033-2909.127.1.87

Freitas, P. G. (2008). Drawing the Human Figure and the Drawing of the Sick Person in Psychological Assessment of Children in Hospital. 140 f. Dissertation Master, São Paulo: Institute of Psychology, University of São Paulo.

Hultz, C. S., \& Bandeira, D. R. (2000). Human Figure Drawing. In Psychodiagnosis-V (5th ed., pp. 19-22). Porto Alegre: Artmed.

Kubler-Ross, E. (2008). On Death and Dying: What the Terminally Ill Have to Teach Doctors, Nurses, Religious and Their Own Relatives (9a. ed.). São Paulo: Editora WMF Martins Fontes.

Moraes, E. O., \& Enumo, S. R. F. (2008). Hospitalization Coping Strategies in Children Evaluated by Computerized Instrument. Psycho-USF, 13, 221-231.

Oliveira, G. F., Dantas, D. F. C., \& Fonseca, P. N. (2004). The Impact of Hospitalization in Children 1 - 5 Years of Age. Journal of the Brazilian Society of Health Psychology, 7, 3-12.

Simonetti, A. (2004). Manual of Health Psychology: The Disease Map. São Paulo: House of Psychologist.

Stout, C. E., \& Cook, L. P. (1999). New Areas for Psychological Assessment in General Health Care Settings: What to Do Today to Prepare for Tomorrow. Journal of Clinical Psychology, 55, 797-812. http://dx.doi.org/10.1002/(SICI)1097-4679(199907)55:7<797::AID-JCLP3>3.0.CO;2-O

Valle, E. R. M., \& Ramalho, M. A. N. (2008). The Cancer in Children: The Difficult Path. In Themes in Psycho-Oncology. São Paulo: Summus.

Veit, M., \& T. Carvalho, V. A. (2008). Psycho-Oncology: Definitions and Scope of Business. In Themes in Psycho-Oncology. São Paulo: Summus.

Veit, M. T., \& Barros, L. H. C. (2008). Interventions in Psycho-Oncology Institutions. In Themes in Psycho-Oncology. São Paulo: Summus. 


\section{Appendix}

\section{Hospital Service Psychology Anamnesis to Child and Adolescent}

\section{1) IDENTIFICATION PATIENT}

Name

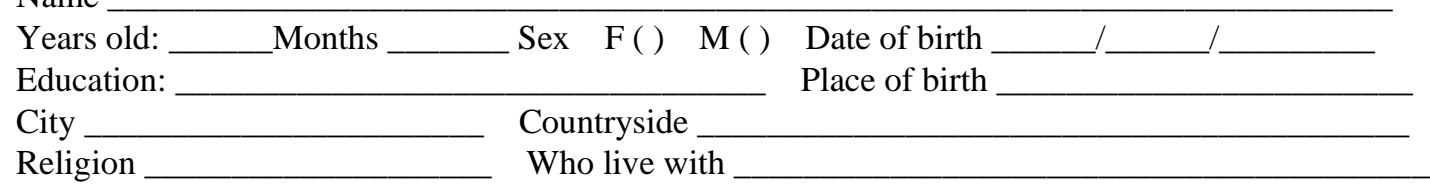

2) IDENTIFICATION OF RESPONSIBLE

Father's/ Mother's name:

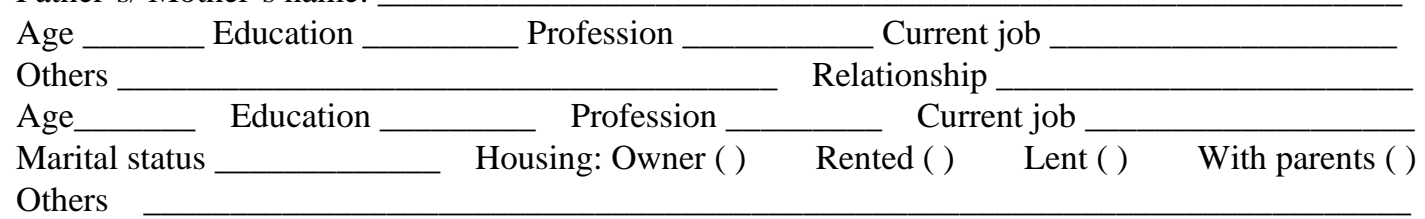

\section{3) REASON FOR HOSPITAL}

Do you know why the child/adolescent is hospitalized?

How did the symptoms appear?

What happened after the onset of symptoms to the first hospitalization?

\section{4) HOSPITAL}

First hospitalization? Yes ( ) No ( ) Number of hospitalization:

Are you aware of the clinical/diagnostic state? Yes ( ) No ()

How are the first days of hospitalization?

How has been the sleep in this period?

How have you been eating?

How did you eat before becoming ill?

Attitude assessment towards the hospitalization: discouragement ( ) fear ( ) desperation ( ) tranquility ( ) others

Relationship with the health team: Good ( ) Fair ( ) Bad ()

Regarding the care provided by the staff: Refusal ( ) Passive ( ) Collaborative ( )

Regarding to the treatment: Adherence ( ) No adherence ( )

\section{5) PERSONAL HISTORY}

How long after the wedding/marriage took place pregnancy?

It was planned?

It was the first pregnancy?

How was the reaction of parents with the news of the pregnancy?

Had abortion, natural or caused?

Stillbirths

Dead children

\section{6) PREGNANCY}

How did you physically feel during this period?

And emotionally?

Did Prenatal?

Was hospitalized?

Used medicine?

Made radiography or anesthesia?

When you felt the baby move for the first time?

Some remarkable event in this pregnancy? 
Did you feel different from the others in some way?

What fears about pregnancy?

7) BIRTH

Place: Do you know who helped you?

The father was present?

How long was the labor of birth?

Describe how was it?

The position of the child at birth was correct?

Had some congenital anomaly?

Weight__ Height

How long it took to be discharged:

\section{8) POSTPARTUM}

Became depressed?

How did you feel before the child?

Who took care of the child?

9) FIRST YEARS OF LIFE

Was breastfed? Yes ( ) For how long? No ( ) Why?

How was the sequence the bottle-baby food?

For how long

Has preference for sweet or salty?

When the child started to walk?

When began the training of sphincters?

Used pacifier? __ In what situation?

Sucked finger __ In what situation?

How?

Had a special attachment object?

When did you use it?

Was communicative ( ) Extrovert ( ) Timid ()

Hurt ever seriously?

Get dressed by themselves?

Bathing alone?

Wears shoes?

10) SLEEPING

How sleeps the child/teenager?

Usually goes to parents bed at night?

What is the attitude of the parents?

During sleep: grind teeth?

Tell dreams-what types?

\section{1) LANGUAGE}

When the child began to speak and what the first words:

Exchange any letter, stutters, in what situation:

\section{2) EDUCATION}

When the child began to attend school, why?

Describe the first day of school:

Reproached ever?

Some school report?

How is the relationship with other students?

And with the teacher?

13) SOCIAL SKILLS AND PLAYFUL

With whom prefers to play? 
Usually make friends?

Prefers a toy/games?

Which age group?

How does the child react when they request a toy and not given to it?

What is the attitude of parents?

Belongs to groups in social networks?

The child belongs to a group at school or outside school?

Has a friend in particular?

\section{4) SEXUALITY}

When started presenting sexual curiosity?

Showered with parents?

Masturbates?

How?

How long?

In what circumstance?

From what age?

Has sex in what situation?

15) DISEASES

Which has had?

Had surgery? When?

There was a change in behavior after surgery, such as:

How behaves when is sick?

What is the attitude of the parents?

Are there any cases of illness in the family, which one?

Any cases of alcoholism, physical or mental disability suicide?

16) FAMILY RELATIONSHIP

How they met and decided by the union?

How parents relate to their children?

How is the couple's relationship?

Of whom the child/adolescent is afraid?

Why?

Has siblings? How many?

There are other people living in the house?

How is the patient's relationship to them?

Manaus

Parent/Guardian

Researcher/Psychologist 